\title{
On the Construction of Reverse Proverbs
}

\author{
Fei Deng \\ School of Foreign Languages, Sichuan University of Arts and Science, Dazhou, Sichuan, China
}

\begin{abstract}
Proverbs are the essence of language and culture, which are concise in speech but contain lots of connotations. And they are the summary of people's daily life as well as people's wisdom. Meanwhile proverbs have the characteristics of refinement, nationality, religion, region and stability. With the change of times, some proverbs are obviously out of date, dying out gradually, and some proverbs continue to develop and bring forth some new ones. Through reverse thinking, adopting word order shift, word change, parody, ellipsis and antonym to construct a new one. The foundation of its construction depends on many factors such as the text information of the original proverbs and the scholars themselves.
\end{abstract}

Index Terms - proverb, characteristics, reverse thinking, construction

\section{INTRODUCTION}

Proverbs are the crystallization of people's wisdom and the summary of social practice and daily life experience. The structure of proverbs is diverse, its content is all-inclusive, its language is concise and vivid, and it is funny, humorous. The classical proverbs have been handing down from generation to generation and become treasures of human civilization. With the change of the times and the subversion of ideas, some proverbs have been called into question. The human beings have created more new proverbs according to the context based on the reverse thinking, and which have been spread to different groups of people in daily life.

\section{THE DEFINITION OF PROVERBS}

\section{A. The Definition of Proverbs in Ancient Books}

It is originated from the Pre Qin Period (i.e. before 221 B.C. when the First Emperor of Qin united China). Different people have different opinions on what is proverb. In The Book of Rites, it is "common saying", in Hanshu it is "vulgar and good rumors", and in Origin of Chinese Characters, it is "previous ancient motto".

\section{B. The Definition of Proverbs in Modern Reference Books}

In $\mathrm{Ci} \mathrm{Hai}$, proverbs are popular, concise and meaningful sentences which are deeply loved by people, which mainly reflect people's experience in life (Compilation Committee of Cihai, 1979). In Xinhua Dictionary, proverbs are fixed sentences with profound meanings and simple words that are popular among the people.

In Longman Modern Dictionary, proverb is "a brief familiar maxim of folk wisdom, usually compressed in form, always including a bold image and frequently a jingle that catches the memory". In Longman Contemporary English-Chinese Dictionary, it is "a short well-known saying usu. in popular language". In Oxford Advanced English-Chinese Dictionary, it is "short well-known saying that states a general truth or gives advice". And in Random House Webster's Dictionary of American English, it is "a short popular saying that expresses effectively some common place truth or useful thought".

\section{The Definition of Proverbs by Domestic Scholars}

In A Study of Proverbs, proverbs are rhythmic and beautiful words that regulate people's behavior in daily communication and are the result of practical experience (Guo Shaoyu, 1925).

In Proverbs, it explains the structure, nature and content of proverbs in details, and defines it as "Concise and popular, humorous and witty rhymes, which have been circulating for a long time, are ready-made words to summarize people's feelings and experiences in daily life" (Wu Zhankun, 1980).

In Chinese-English Proverbs and Culture, proverbs are relatively complete sentences with rhythm, popularity, vividness and conciseness, which are derived from people's practical life experience and contain specific cultural colors (Wang Dechun, 2003).

Wen Duanzheng not only summarized the previous scholars' research on proverbs, but also explored the construction, semantics, grammatical functions, cultural connotations and rhetoric of proverbs. He considered proverbs to be "sayings for the purpose of imparting knowledge" (Wen Duanzheng, 2006).

From the different definition of proverbs, it can be seen that proverbs are the essence of language and culture, with concise words but rich cultural connotations. They are the summary of people's daily life, the crystallization of wisdom, and they have strong national colors as well as play an important role in promoting national language and culture.

\section{THE CHARACTERISTICS OF PrOverbS}


In terms of language form, proverbs belong to idioms and have many similarities with mottos, allegorical sayings and idioms. However, they are also a language form with its own unique characteristics, which can be summarized as following aspects:

\section{A. Conciseness}

The form of proverbs is short and concise. As far as its format is concerned, there are one-sentence pattern, two-sentence pattern, three-sentence pattern, four-sentence pattern and multiple-sentence pattern. For example: (1)Every second counts (Yang Zengmao, 2003). There are only three words to express the importance of time, which means "An inch of time is an inch of gold." or "Time is money." (2)The best go first (Yang Zengmao, 2003). There are four words to make it clear that the best is to go first.

From the sentence structure and semantics, it can be found that the form of proverb is short and concise but with profound implications.

\section{B. Nationality}

Proverbs are a kind of language with nationality. "Proverbs often have distinct national characteristics in materials, forms, rhetoric and even sentence structure (Wu Susu, Zeng Shufang, 2010).” Taking "dog” for example, it always has negative meanings in Chinese proverbs. "Every dog is valiant at his own door." means "be a bully under the protection of a powerful person". However, westerners regard dogs as their most faithful partners and friends, and let them accompany them day and night. The most famous proverb about dogs is "Qui me amat, amat et canem meam." it is Latin, from St. Bernard in the 12th century. Another one is "It's hard to teach an old dog new tricks.", originated in the early 17 th century, it means that when dogs get old, they can no longer serve their owners, let alone learn new tricks.

The nationality in Chinese and English proverbs respectively reflects the different thinking mode and the different development history of different nationalities, which expresses the rich cultural connotation of their own nationalities.

\section{Religiosity}

Religious language is an important part of human culture, and it is a universal social phenomenon. "Proverbs are closely related to culture, which can reflect the influence of religion on language (Ping Hong, Zhang Guoyang, 2012).” To some extent, the cultural background, customs and characteristics are influenced by different religions. The religiosity is obvious in Chinese and English proverbs. Buddhism, Taoism and Confucianism in China have a far-reaching impact on Chinese development and the development of language and culture. But most English-speaking countries are Christian, whose language, including proverbs, is largely influenced by the image in the doctrine. Undoubtedly, most proverbs handed down are labeled with religion (Wu Jie, 2013).

Taking Chinese proverb "One never goes to the temple for no reason." for example. "Three treasure palaces" generally refers to the general Buddhist temple, and ordinary people cannot enter to play casually except do prayer, worship and other related faith activities. The proverb is used to describe that one would not go to someone's place except on business. However, English proverbs are always related to Christianity. Such as:

God helps those who help themselves (Li Wei, 2007).

Better to reign in hell than serve in heaven (Yang Zengmao, 2003).

The devil dances in an empty pocket (Yang Zengmao, 2003).

\section{Regional}

Language culture is closely related to the natural geographical environment. People living in different regions form different cultures and the frequency of using language are also different, showing obvious regional differences (Ma Lijun, Zhang Jijia, 2017). People living in different regions have accumulated different proverbs. One of the most representative proverbs is "sweet in the south, salty in the north, spicy in the east and sour in the west", which introduces Chinese dietary habits. "Sweet" mainly refers to Su cuisine. People in Jiangsu and Zhejiang province are famous for their sweet food. "Salty" refers to Shandong cuisine in the north. "Spicy" refers to Hunan and Sichuan cuisine that "people in Hunan and Sichuan are not afraid of spicy". "Sour" mainly refers to Shanxi people who love vinegar very much. It is said that they often drink vinegar first before eating.

Britain is an island country surrounded by many islands, with a winding coastline and rich sea water, which is very beneficial to the development of fishing and navigation industry. In such a favorable geographical environment, there are many proverbs and idioms related to navigation and fishing. Taking "fish" for example:

Do not teach fish to swim (Yang Zengmao, 2003).

Fish goes rotten by the head (Yang Zengmao, 2003).

Go to the sea, if you fish well (Yang Zengmao, 2003).

It is good fishing in troubled waters (Yang Zengmao, 2003).

\section{E. Stability}

Proverbs are the summary of human daily life and experience. Whether synchronically or diachronically, each component is usually inseparable, that means, it has relative stability (Deng Fei, 2011). That is to say, once a proverb is formed, the combination of sound and meaning in a certain period is relatively stable and cannot be changed. For 
example: (1) Kill two birds with one stone. / Kill two vultures with one arrow (Li Wei, 2007). "Stone" cannot be replaced by "rock" and "vulture" cannot be replaced by "eagle". (2)March winds and April showers bring forth May flowers (Yang Zengmao, 2003). The words "March", "April” and "May" in the original sentence cannot be changed into some other months casually.

\section{Literature ReVIEW OF PROVERBS}

\section{A. Literature Review of Chinese Proverbs}

The study of modern proverbs began in the first half of the 20th century. During this period, people have a clear understanding of the nature of proverbs, and have made remarkable achievements in theoretical research, which has basically changed the tendency of focusing on corpus collection, ignoring theoretical research, focusing on sources rather than interpretations, and focusing on classics rather than oral English. According to Wen Duanzheng, the study of proverbs in modern China can be divided into four periods (Wen Duanzheng, 2000):

a) From the beginning of the 20th century to the founding of New China

The representatives of this period are Guo Shaoyu, Xue Chengzhi, and Wang Shun etc. In A Study of Proverbs, the author firstly replaced the broad understanding of proverbs in ancient times with the narrow understanding of proverbs, and made a comprehensive and systematic analysis of the contents and forms of proverbs, and compared proverbs, ballads, maxims and fables with other language forms that are easily confused (Guo Shaoyu, 1925). Wang Shun's On Agricultural Proverbs in the Northern Xia Dynasty discussed the agricultural proverbs and their functions, and analyzed the epochal and local characteristics of agricultural proverbs, creating a precedent for the collection, collation and research of agricultural proverbs. Xue Chengzhi first proposed that proverbs are a form of language and belong to folklore. And he discussed the nature, content and expression of proverbs, and investigated the evolution of ancient and modern proverbs in China. The author also distinguished proverbs from ballads, idioms, maxims and allegorical sayings.

b) From the founding of New China to the beginning of Reform and Opening-up

The study of proverbs from the founding of New China to the early 1980 s is closely related to the politics at that time. The study of proverbs in this period paid more attention to the discussion of contents, classification and characteristics of proverbs, paid more attention to the study of folk proverbs, regarded proverbs as a kind of idioms, and gradually began to study proverbs from the perspective of linguistics, especially lexicology. The main research achievements of this period are as follows: Ma Guofan's The Characteristics of Proverbs, Yang Xin'an's The Difference between Idioms and Proverbs, and Wang Yi's On Chinese Proverbs etc.

c) From the Reform and Opening-up to the 21 st century

Influenced by theoretical linguistics, the study of proverbs in this period reached its peak in the breadth and depth. In terms of breadth, the research of proverbs in this period includes the nature, content and form of proverbs, as well as the structure of proverbs. In addition, some achievements have been made in the study of the functions of proverbs, including their social functions, grammatical functions and rhetorical functions. The main works are Wu zhankun and Ma Guofan's Proverbs (1980), Wang Qin's Introduction to Proverbs (2006), Wen Duanzheng's Proverbs (2000). There are also some achievements related to the comparative study of Chinese and English proverbs, such as Yu Fumin and Guo Shanlian's English and Chinese Idioms (1999), and Jiang Lei's Cultural Observation and Comparison of English and Chinese Idioms (2000). In terms of depth, the research of proverbs in this period pays attention to the linguistics research of proverbs, explores the internal rules of proverbs in form, from phonetics, grammar, rhetoric, semantics, and other structures and features. In the process of research, we should widely use the theories and methods of modern linguistics in content, pay attention to the cultural connotation and cross-cultural differences of proverbs, and take knowledge as the essential features of proverbs, such as Sun Weizhang's Chinese Idioms (1988).

d) In the 21 st century

In the 21 st century, the study of proverbs is no longer limited to the classification and description of proverbs' structure, semantic features and cultural features, but uses the theories and methods of modern linguistics (e.g. contrastive linguistics, cognitive linguistics, psycholinguistics, etc.) to research on the formation mechanism, understanding and social function of proverbs. Wang Dechun's Chinese and English Proverbs and Culture (2003), Zhang Hui's Cognitive Semantics of Chinese Idioms (2003) and Wang Qin's On Chinese Idioms (2006) are representative works of this period.

\section{B. Literature Review of English Proverbs}

Similar to Chinese proverbs, most proverbs in the early western originated from maxims with important meaning. The outstanding feature of early western proverbs is that they are closely related to religion. The study of western proverbs can be traced back to The Book of Proverbs in the Old Testament, collected by King Solomon of ancient Israel.

a) A study of ancient English Proverbs

The earliest study of proverbs in England was found in a letter preserved by the Anglo-Saxon missionary Boniface in the middle of the 7th century. For example: A coward often misses glory in some high enterprise; therefore he dies alone The earliest collection of English proverbs is John Heywood's Dialogue of English Proverbs in 1546. After that in 1614 Camden published Remains Concerning Britain and in 1641 David Ferguson published Scottish Proverbs. The research 
of English early proverbs mainly focuses on the collection of materials and the textual research of the sources. One of the purposes is to pay attention to practical and educational significance, which is mostly done by missionaries and priests to persuade people in daily life. In 1823 Issac D'Israeli`s The Philosophy of Proverbs is an early academic study of English proverbs.

b) A study of modern English Proverbs

At the beginning of the 20th century, the revolution of Saussure's linguistics in Europe marked the birth of modern linguistic theory, from which the study of linguistics stepped into a new period. In the middle and late 20th century, the rise of cognitive linguistics changed the way people used to study proverbs, began to pay attention to the cognitive understanding of semantics, and explained proverbs from the perspective of the relationship between language and thinking. Archer Tylor, Wolfgang Mieder, Raymond W. Gibbs, Richard P. Honeck are representatives of the study of proverbs in this period. In 1997 Richard P. Honeck`s A Proverb in Mind: A Cognitive Science of Proverbial Wit and Wisdom is one of the representative works of this period. The book focuses on three theoretical models of proverb understanding from the perspective of cognitive linguistics: the Extended Conceptual Base Theory, the Great Chain Metaphor Theory, and the Dual Coding Theory. He pointed out that the history of proverbs was interesting but unclear. The only way to learn about the earliest use time of proverbs is by writing them down.

From the study of English and Chinese proverbs, it can be seen that although scholars have done a lot of research on proverbs for a long time, due to various reasons, these studies are not enough, and they pay far less attention to proverbs than idioms. From the previous research, the research mainly focuses on the definition of proverbs and the comparison with other idioms, the relationship between proverbs and culture, the rhetorical features of proverbs, the translation of proverbs and the comparison between Chinese and English proverbs. However, there are few researches on the reconstruction of proverbs.

\section{The Construction of Reverse Proverbs}

Proverbs are the essence of a nation's language and culture, which reflect people's observation of nature, society, the world, family and interpersonal relationship with simple and concise sentences. And they are the summary of People's daily life experience and the crystallization of wisdom. For a long time, domestic scholars have focused on static studies of proverbs in terms of categories, construction, characteristics, rhetoric, grammatical functions and cultural connotations (Zha Qinglan, 2013). However, in the network age, some proverbs are outdated and then gradually die out, while some proverbs keep developing and bring forth the new ones. Therefore, reverse thinking of these classical proverbs from the structure, wording, style, implication and other aspects, and then reorganize the so-called classical proverbs, so as to construct a new proverb. Generally speaking, the construction of reverse proverbs can be summarized as follows:

A. Exchange: the meaning and implication of proverbs will be changed by exchanging some words` positions. For example:

All one`s geese are swans (Christine Ammer, 2005).

$\longrightarrow$ All one`s swans are geese.

The original proverb means one is over exaggerating and not in touch with reality. As is known to all, goose and swan are quite different, the goose is proverbially contrasted with the swan as being the clumsier, less elegant, and less distinguished bird, so to think they are the same is a stretch of the truth. After changing the positions of the two words: geese and swans, the reverse proverb refers to "get the opposite of what one wants", "achieve the opposite of what one intended".

Where love is, there is faith (Yang Zengmao, 2003).

$\longrightarrow$ Where faith is, there is love.

The original proverb means loyalty or trust comes with love. Love should be based on "trust", but in reality, many people lack trust in love and are suspicious of each other. Although some couples know the word "trust", but do not have the sense of trust, let alone how to do trust each other. So: where faith is, there is love.

B. Replace: the syntagmatic relation of proverbs remains stable, but replace some words with others only from the paradigmatic relation. According to Saussure, syntagmatic relation refers to the combination based on sequentiality. Words are used in discourse, strung together one after another, and enter into relations based on the linear character of languages. Paradigmatic relation is a connection in the brain. This kind of connection between words is of quite a different order (Hu Zhuanglin, 2008). For instance:

Harm set, harm get (Yang Zengmao, 2003).

$\longrightarrow$ Harm watch, harm catch.

"Set" and "get" in the original proverb are replaced by "watch" and "catch" to express the similar meaning "Harm others and themselves eventually."

A bird in the hand is worth two in the bush (Ai Chaoyang, 2009).

$\longrightarrow$ A feather in hand is better than a bird in the air.

The original proverb is from Aesop's Fables, which means that a bird in the hand is better than two birds in the tree. Also means that the small present interests are more practical and reliable than the greater future interests. Meanwhile it is also to remind people of treasuring what you have. "A feather in hand is better than a bird in the air." 
C. Parody: To imitate the structure of the original proverbs, and replace some words to create new proverbs in order to achieve the purpose of ridicule, or satirize, especially to imitate those well-known classic proverbs. Such as:

It's hard to teach an old dog new tricks (Christine Ammer, 2005).

$\longrightarrow$ It's hard to teach an young dog old tricks.

The original proverb means that "Someone who is used to doing things a certain way cannot change" or "You cannot teach some new skill or behavior to someone who is set in their ways". However, the modern young people are in pursuit of new trends, and have little knowledge of traditional old things. Therefore, it is difficult for them to learn and accept the old things, that is to say: It`s hard to teach an young dog old tricks.

Better a red face than a black heart (Yang Zengmao, 2003).

$\longrightarrow$ Better a black heart than a red face.

The implication of the original proverb is that people should have a sense of shame and do something but not everything. However, nowadays, many people are crazy about pursuing material interests, and they will do anything in order to achieve their goals: Better a black heart than a red face.

D. Abridgement: It refers to the deletion of some words or phrases in the original classical proverbs, so as to form a new proverb. The structure of the new proverb appears shorter and more concise, which can also stimulate learners' association of the semantic structure of the original proverb. For example:

Time flies like an arrow.

$\longrightarrow$ Time flies

The complete sentence is "Time flies like an arrow, fruit flies like an apple." The two sentences have the same structure but different semantics because the parts of speech and semantics of "flies" and "like" are different. In the first half of the sentence, "flies" is a verb, means "flying", "like" is a preposition, means "same". In the second half of the sentence, "flies" is a noun, means "flies (one kind of insect)", "like" is a verb, means "love".

Try your friend before you trust him.

$\longrightarrow$ Try before you trust.

The original one means "A friend must be tested before he can be trusted". It is deleted into "Try before you trust", that can also be deduced as "Try before you buy". That is to say, whatever you do, you should try it first.

E. Antonymy: According to the original proverb, reconstruct another proverb which is completely opposite in meaning. Such as:

Crows do not pick out crow`s eyes (Ai Chaoyang, 2009).

$\longrightarrow$ Crows pick out crow`s eyes.

The original proverb means "One shouldn't hurt or attack a colleague." Or "Dogs do not eat dogs." But in the cruel and ruthless society, dogs bite dogs, people eat people, that is to say: Crows pick out crow`s eyes.

Many a good cow has an evil calf (Yang Zengmao, 2003).

$\longrightarrow$ Many a good cow has a good calf.

Distinguished families usually have absolute authority. In order to maintain authority, extreme education methods are often adopted. The halo effect, which was put forward by the famous American psychologist Edward in the1920s, increases their own psychological anxiety and also increases their children`s psychological pressure. Ultimately, it leads to "Many a good cow has an evil calf."

While throughout history, "Many a good cow has a good calf." There are many examples: In ancient times, Da Yu, the third of the three legendary emperors who created China and his son Xia Qi are a good example. In Song dynasty, Su Xun, Su Shi, and Su Zhe are the same example. In Yuan dynasty, Tiemuzhen, Torre and Kublai Khan created the largest territory in the world and so on and so forth.

\section{CONCLUSION}

The ever-changing development of society promotes the continuous development of language, and Chinese and English proverbs are no exception. In addition to the above-mentioned characteristics, Chinese and English proverbs also have the characteristics of traditionality, artistry, popularity, practicality, rhetoric and so on. Of course, the construction of reverse proverbs is not only reflected in the five aspects mentioned above, but also in the specific context, the speaker should draw inferences from one another and create more reverse proverbs by analogy, deduction and recreation according to the actual situation. The construction of reverse proverbs proves once again that "life needs to be questioned and ideas need to be subverted", which is based on many factors such as the text information of the original classical proverbs and the level of scholars themselves.

\section{REFERENCES}

[1] Ai Chaoyang. (2009). Cultural Images In English Proverbs An English-Chinese Dictionary. Beijing: Jindun Press, 45.

[2] Christine Ammer. (2005). Cool cats, Top Dogs, and Other Beastly Expressions. Beijing: Foreign Language Teaching and Research Press, 170.

[3] Compilation Committee of Cihai. (1979). Cihai(Compact Edition). Shanghai: Shanghai Lexicographical Press, 398.

[4] Deng Fei. (2011). On Variation of Animal Proverbs: Anti-proverbs. Journal of Chongqing University of Technology, 7, $107-111$.

[5] Guo Shaoyu. (1925). A Study of Proverbs. Shanghai: The Commercial Press. 
[6] Hu Zhuanglin. (2008). Linguistics Course. Beijing: Foreign Language Teaching and Research Press, 94.

[7] Jiang Lei. (2000). Cultural Observation and Comparison of English and Chinese Idioms. Wuhan: Wuhan University Press.

[8] Li Wei. (2007). English Proverbs from A to Z. Shanghai: East China University of Science and Technology Press, 94.

[9] Ma Lijun, Zhang Jijia. (2017). The Nature of Semantic Properties and Their Inter-relationships in Chinese Proverbs. Journal of Zhejiang University (Humanities and Social Sciences), 3, 42-54.

[10] Ping Hong, Zhang Guoyang. (2012). English Idioms and Anglo-American Culture. Beijing: Foreign Language Teaching and Research Press, 109.

[11] Richard P. Honeck. (1997). A Proverb in Mind: A Cognitive Science of Proverbial Wit and Wisdom. New Jersey: Lawrence Erlbaum.

[12] Sun Weizhang. (1988). Chinese Idioms. Changchun: Jilin Education Press.

[13] Wang Dechun. (2003). Chinese-English Proverbs and Culture. Shanghai: Shanghai Foreign Language Education Press, 18.

[14] Wang Qin. (2006). Introduction to Proverbs. Jinan: Shandong Education Press.

[15] Wen Duanzheng. (2000). A Study of Chinese Idioms in the 20th Century. Shanxi: Shuhai Press, 7.

[16] Wen Duanzheng . (2006). Proverbs. Beijing: The Commercial Press, 14.

[17] Wu Jie. (2013). On the Cultural Connotation Difference from English and Chinese Proverbs. Journal of Yangtze University (Social Sciences Edition), 9, 121-122.

[18] Wu Susu, Zeng Shufang. (2010). Dealing with Cultural Differences in Translation of English-Chinese Proverbs: Foreignization and Domestication. Journal of Teaching and Management, 6, 78-80.

[19] Wu zhankun, Ma Guofan. (1980). Proverbs. Hohhot: Inner Mongolia People's Press, 32.

[20] Yang Zengmao. (2003). Bilingual English Proverbs. Beijing: Jindun Press, 39.

[21] Yu Fumin, Guo Shanlian. (1999). English and Chinese Idioms. Shanghai: Shanghai Jiaotong University Press.

[22] Zha Qinglan. (2013). Cognitive Interpretation of Chinese Proverbs from the Perspective of Conceptual Integration Theory. Jiangxi Social Sciences, 9, 206-210.

[23] Zhang Hui. (2003). Cognitive Semantics of Chinese Idioms. Beijing: Military Yiwen Press.

Fei Deng was born in Sichuan, China in 1981. He is currently an associate professor in the School of Foreign Languages, Sichuan University of Arts and Science, Sichuan, China. He has finished 4 scientific research subjects and published 26 papers in journals. He is a member of Sichuan Applied Foreign Languages Institute. His research interests include Foreign Language Teaching, and Translation Theory and Practice. This work is a periodic achievement of A Rhetorical Study of Reverse English and Chinese Proverbs (2017KR004Y) supported by Sichuan University of Arts and Science. 